\title{
Study of the Moisture Absorption in Polymer Composites Reinforced with Vegetal Fiber Using Langmuir's Model
}

\author{
Wanessa Raphaella Gomes dos Santos ${ }^{a *}{ }^{\oplus}$, Mirenia Kalina Teixeira de Brito ${ }^{a}$, \\ Antônio Gilson Barbosa de Lima ${ }^{a}$ \\ ${ }^{a}$ Programa de Pós-Graduação em Engenharia de Processos, Universidade Federal de Campina \\ Grande, Campina Grande, Paraiba, Brasil
}

Received: December 12, 2018; Revised: September 25, 2019; Accepted: October 10, 2019

\begin{abstract}
This work aims to numerically study the moisture absorption in polymer composites reinforced with vegetal fiber, using the diffusive model of Langmuir, which considers the existence of water molecules inside the material free to diffuse and adsorb at the capillaries walls, in the solid. A threedimensional and transient mathematical modelling to describe the water absorption process by the composite and its numerical solution via finite volume method are presented and discussed. Results of the free solute concentration, entrapped solute concentration, local moisture content and average moisture content obtained at different instants of the process are presented and analyzed. It was verified that the concentration gradients of the molecules (free and entrapped) are higher at the material surface. In addition, as the concentration of free water increases, there is also an increase in entrapped water concentration within the material at any time of the process.
\end{abstract}

Keywords: polymer composites, vegetal fibers, Langmuir model, numerical solution.

\section{Introduction}

Composites are materials formed by the combination of two or more materials, insoluble in each other, forming a useful engineering material, that has certain properties and that are not obtained by its constituents separately ${ }^{1}$.

Generally, a composite is constituted by a matrix (continuous phase that completely involves the disperse phase) and a reinforcement (discontinuous phase or dispersed in the form of fibers, spherical particles or platelets), that provides different structures and properties to the material.

In relation to the reinforcement types that can be used in the composites, the vegetal fiber is highlighted. In comparison to the traditional synthetic reinforcement agents, the vegetable fibers present lower density, abrasiveness and cost, besides, they are biodegradables and renewable. Its mechanical performance can be compared to the synthetic fiber performance and they present good thermal properties ${ }^{2}$, which justifies its use as a reinforcement in polymers. So, the use of vegetable fibers presents high potential in technological application due to its use as a substitute of synthetic fiber. The production of those fibers presents a great socioeconomic character, especially in Brazil, where they are produced by communities of the north and northeast regions ${ }^{3}$.

The main disadvantages of the vegetable fibers as a polymer composite reinforcement are its susceptibility to the influence of environmental agents, non-uniformity and low mechanical properties, especially at high temperature. Besides the non-polar characteristics of the thermosetting resins. So, the knowledge of the hygrothermal behavior of the composite reinforced by vegetal fibers becomes essential to a better use of this type of material and its properties in materials used in engineering. From this, the moisture absorption mechanisms in polymer materials have been object of numerous studies and suggest that the sorption dynamic is very complex and depends on the type of the polymer, conditions and experiences realized ${ }^{4}$.

Moisture absorption in composites can degrade the mechanical properties by three different mechanisms: the first involves the water molecule diffusion within the microlacts between the polymer chains; the second involves the capillary transport in gaps and faults at the interfaces between fiber and matrix, and the third mechanism is associated with swelling effects that propagate microcracks in the matrix ${ }^{5}$. In addition, the hygrothermal exposure can reduce the glass transition temperature of the polymers and cause plastification of the polymer matrix resulting in the decrease of the dominant resistance properties of the matrix. The hygrothermal effect increases the internal voids, promotes chain expansion and forms microcracks in the polymer matrix ${ }^{6}$.

The description of the phenomenon of water absorption in solids has been studied in the literature for years and it already has many models of water absorption defined. Among the most widely studied and used, the Fick's model is highlighted due to the easy of fitting the equation of the model to the sorption data?

The Fick's law is a common model to represent a diffusion process where every water molecule is free to move in a polymer chain ${ }^{8}$. The suitability of the Fick's model to the absorption 
process is reduced with the increase of the temperature and/ or the moisture as the diffusion mechanism becomes less dominant, and the other mechanisms such as, the interaction polymer-penetrant and/or the relaxion of the polymer begin to have an increasing effect in the moisture transportation? ${ }^{7}$. Hence the need to study other complex models that comprehend this difference of behavior. In this context, the Jacob's- Jones model $^{9}$, the variable diffusivity model depending on the time ${ }^{10}$ and the Langmuir's model ${ }^{11}$, can be cited.

In Langmuir's model, for instance, one quantity of the water molecules is free to move while the complementary quantity is connected to the polymer chains due to reversible chemical reactions such as that occurring when moisture-induced plastification occurs. A free water molecule can become an entrapped molecule and, mutually, an entrapped water molecule can become free. These effects are computed in the model by using two additional parameters: $\lambda$ (probability of a free water molecule being entrapped) and $\mu$ (probability of an entrapped molecule becomes free $)^{4,12}$. Although Langmuir's model enables the incorporation of additional effects not contemplated by the Fickian model due to the inclusion of the effects of $\lambda$ and $\mu$, estimated by Joliff's methodology ${ }^{13}$, the difficulty of obtaining these parameters causes the absence of studies on the subject, limiting the use of the model. Thus, the development of studies on the Langmuir model with the objective of making its use feasible to deal with the limitations of more usual and less complete models, such as the Fick model, which, although satisfactorily models the initial moisture uptake regions, promotes a discrepancy between the proposed and the experimental model for final process times.

So, the object of this work is to develop a transient and three-dimensional mathematical modelling and its numerical solution (via finite volume method) to predict the mass transfer during the water absorption in a polymer composite reinforced by vegetal fiber via Langmuir's model.

\section{Mathematical Modelling}

\subsection{The physical problem}

The physical problem to be studied is the absorption of water into a solid material with a geometry of a parallelepiped with dimensions $2 \mathrm{Rx} \times 2 \mathrm{Ry} \times 2 \mathrm{Rz}$ contained in a fluid environment away from the container wall in $1_{x}$ (in the $x$ direction), $\mathrm{l}_{\mathrm{y}}$ (in the $\mathrm{y}$ direction) and $\mathrm{l}_{\mathrm{z}}$ (in the $\mathrm{z}$ direction), according to Figure 1.

For the analysis and solution of the problem the following considerations were made: a) the solid is homogeneous and isotropic, in the form of a parallelepiped, b) constant diffusion coefficient throughout the process, c) transient process, d) there is no variation of the dimensions of the material during the process, e) purely diffusive water transport mechanism, and f) there is no mass generation and g) the solid is completely dry at the beginning of the process.

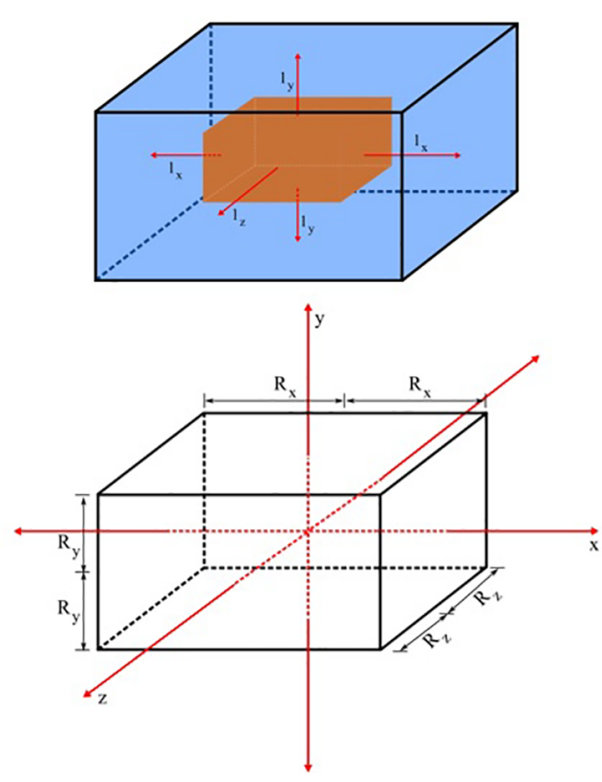

(a)

Figure 1. Scheme of the studied physical problem. a) fluid immersed composite and b) geometric dimensions of the composite.

\subsection{The model}

In the Langmuir model, the non-Fickian moisture absorption behavior can be explained quantitatively by assuming that the moisture absorption consists of two phases, one free water phase and the other entrapped ${ }^{11}$ and is described by the mass transfer equations, as follows:

$$
\begin{gathered}
\frac{\partial C}{\partial t}=\nabla \cdot(D \nabla C)-\frac{\partial S}{\partial t} \\
\frac{\partial S}{\partial t}=\lambda C-\mu S
\end{gathered}
$$

In Equations 1 and 2, $\mathrm{C}$ represents the concentration of the free solute to diffuse into the material, $\mathrm{S}$ represents the concentration of the entrapped solute, $\mathrm{D}$ is the mass diffusion coefficient (free water molecules), $t$ is the time, $\lambda$ is the probability of a free water molecule be entrapped inside the solid, and $\mu$ is the probability that an entrapped water molecules becomes free.

For a three-dimensional and transient approach, and based on the considerations adopted, the Langmuir's model in Cartesian coordinates can be written as follows:

$$
\frac{\partial C}{\partial t}=\frac{\partial}{\partial x}\left(D \frac{\partial C}{\partial x}\right)+\frac{\partial}{\partial y}\left(D \frac{\partial C}{\partial y}\right)+\frac{\partial}{\partial z}\left(D \frac{\partial C}{\partial z}\right)-\frac{\partial S}{\partial t}
$$

where,

$$
\frac{\partial S}{\partial t}=\lambda C-\mu S
$$

For the solution of Equations 3 and 4, the following initial and boundary conditions were used.

a) Initial conditions.

$$
C=S=0 ;\left\{\begin{array}{l}
-R_{\mathrm{x}}<x<R_{\mathrm{x}} \\
-R_{\mathrm{y}}<y<R_{\mathrm{y}} \\
-R_{\mathrm{z}}<z<R_{\mathrm{z}}
\end{array}\right.
$$


b) Boundary conditions.

$1 \frac{\partial C}{\partial t}= \pm D \frac{\partial C}{\partial x}= \pm D \frac{\partial C}{\partial y}= \pm D \frac{\partial C}{\partial z} ;\left\{\begin{array}{c}x= \pm R_{x} ; 1=1_{x} \\ y= \pm R_{y} ; 1=1_{y} \\ z= \pm R_{z} ; 1=1_{z} \\ t>0\end{array}\right.$

Once determined $\mathrm{C}$ and $\mathrm{S}$ at any point within the material, one can calculate the total amount of moisture present in the material at any position and instant of time given by the sum of the concentrations of $\mathrm{C}$ and $\mathrm{S}$, as follows:

$$
M=C+S
$$

Thus, average moisture content is given by:

$$
\bar{M}=\frac{1}{V} \int_{V} M d V
$$

where $\mathrm{V}$ is the total sample volume and $\mathrm{dV}=\mathrm{dxdydz}$. Similar equation was used to calculate the average free water concentration $\overline{\mathrm{C}}$.

\subsection{Numerical solution}

For the three-dimensional solution of the governing equations applied to the moisture absorption in materials with parallelepipedic shape, the approach of the finite volume method was used, with a totally implicit formulation for the concentration of the free solute and explicit formulation for the concentration of entrapped solute. For the discretization of the solid of dimensions $2 \mathrm{Rx} \times 2 \mathrm{Ry} \times 2 \mathrm{Rz}$ symmetrical equivalence and only $1 / 8$ of the solid were used. Figure 2 illustrates a control volume used for the discretization.

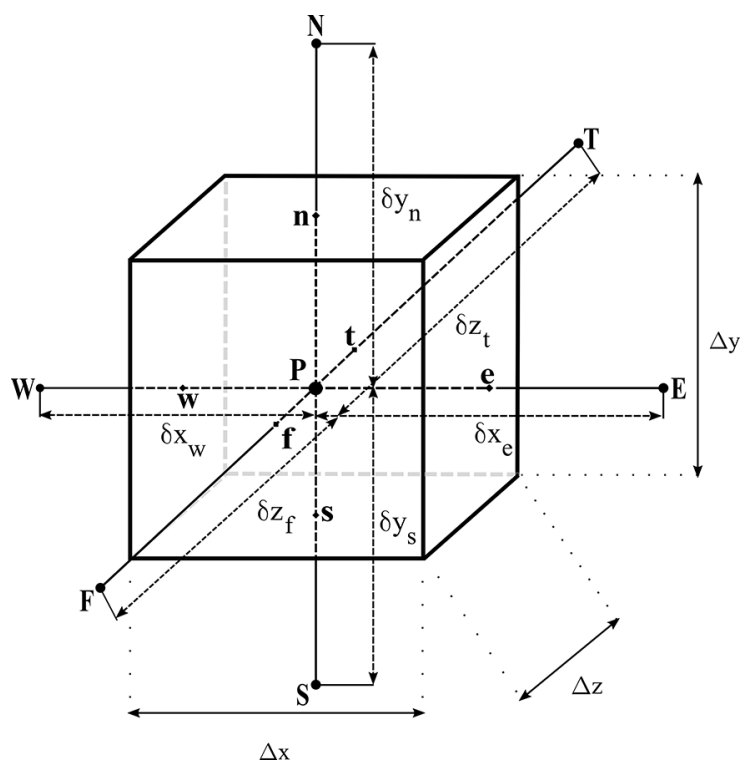

Figure 2. Control volume used in numerical simulation.
The numerical solution is detailed below.

\section{a) Solution to the free water concentration}

The numerical solution of Equation 3 is obtained integrating it in the volume and time as follows:

$$
\begin{aligned}
& \int_{x} \int_{y} \int_{z} \int_{t} \frac{\partial C}{\partial t} d t d z d y d x=\int_{x} \int_{y} \int_{z} \int_{i} \frac{\partial}{\partial x}\left(D \frac{\partial C}{\partial x}\right) d t d z d y d x+ \\
& +\int_{x} \int_{y} \int_{z} \int_{t} \frac{\partial}{\partial y}\left(D \frac{\partial C}{\partial y}\right) d t d z d y d x+ \\
& +\int_{x} \int_{y} \int_{z} \int_{t} \frac{\partial}{\partial z}\left(D \frac{\partial C}{\partial z}\right) d t d z d y d x-\int_{x} \int_{y} \int_{z} \int_{i} \frac{\partial S}{\partial t} d t d z d y d x
\end{aligned}
$$

Assuming a fully implicit formulation, we can write Equation 9 in the discretized form as follows:

$$
\begin{aligned}
& A_{p} C_{p}=A_{E} C_{E}+A_{W} C_{W}+A_{N} C_{N}+A_{S} C_{S}+ \\
& +A_{F} C_{F}+A_{T} C_{T}+A_{P}^{o} C_{P}^{o}+B_{P}^{C}
\end{aligned}
$$

where

$$
A_{E}=\frac{D_{e}}{\delta x_{e}} \Delta y \Delta z
$$

$$
A_{W}=\frac{D_{W}}{\delta X_{W}} \Delta y \Delta z S
$$

$$
A_{N}=\frac{D_{n}}{\delta y_{n}} \Delta X \Delta Z
$$

$$
A_{s}=\frac{D_{s}}{\delta y_{s}} \Delta X \Delta Z
$$

$$
A_{F}=\frac{D_{f}}{\delta z_{f}} \Delta y \Delta x
$$

$$
A_{T}=\frac{D_{t}}{\delta z_{t}} \Delta y \Delta x
$$

$$
A_{P}^{o}=\frac{\Delta x \Delta y \Delta z}{\Delta t}
$$

$$
\begin{aligned}
& A_{p}=\frac{\Delta x \Delta y \Delta z}{\Delta t}+\frac{D_{e}}{\delta X_{e}} \Delta y \Delta z+\frac{D_{w}}{S X_{w}}+\frac{D_{n}}{\delta y_{n}} \Delta X \Delta Z \\
& +\frac{D_{s}}{\delta y_{s}} \Delta X \Delta Z+\frac{D_{s}}{\delta Z_{f}} \Delta y \Delta x+\frac{D_{t}}{\delta Z_{t}} \Delta y \Delta x+\lambda \Delta x \Delta y \Delta z
\end{aligned}
$$

$$
B_{p}^{C}=\mu S_{P}^{o} \Delta x \Delta y \Delta z
$$

It should be noticed that these coefficients are applied to the internal control volumes of the computational domain. For the other control volumes of symmetry and border, proceed with a mass balance in each of them. In total there are 27 different control volume types. Following, the discretization for the control volume of the upper right corner of the computational domain is presented, according to Figure 3. 


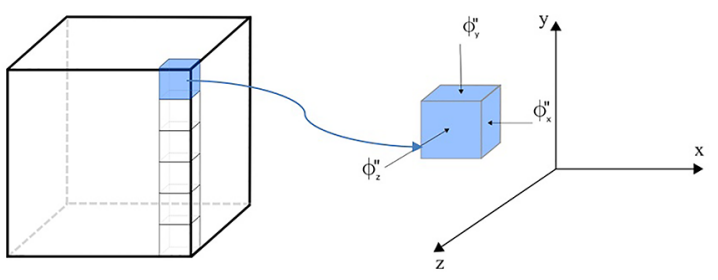

Figure 3. Control volume with mass flow conditions in $\mathrm{x}, \mathrm{y}$ and $\mathrm{z}$ directions.

After the proceeding of integration of Equation 3, in volume and time, for this control volume, the following equation is obtained:

$$
A_{P} C_{P}=A_{W} C_{W}+A_{S} C_{S}+A_{T} C_{T}+A_{P}^{o} C_{P}^{o}+B_{p}^{c}
$$

where

$$
\begin{aligned}
& A_{W}=\frac{D_{W}}{\delta X_{W}} \Delta y \Delta z \\
& A_{s}=\frac{D_{s}}{\delta y_{s}} \Delta x \Delta z \\
& A_{T}=\frac{D_{t}}{\delta z_{t}} \Delta y \Delta x \\
& A_{P}^{o}=\frac{\Delta x \Delta y \Delta z}{\Delta t} \\
& A_{P}=\frac{\Delta x \Delta y \Delta z}{\Delta t}+\frac{D_{W}}{\delta X_{W}} \Delta Y \Delta Z+\frac{D_{s}}{\delta y_{s}} \Delta x \Delta z+\frac{D_{t}}{\delta Z_{t}} \Delta y \Delta x+ \\
& +\frac{\Delta y \Delta x}{\left(\frac{\delta z_{f}}{D_{f}}\right)+\frac{\Delta t}{1_{z}}}+\frac{\Delta z \Delta x}{\left(\frac{\delta y_{n}}{D_{n}}+\frac{\Delta t}{1_{y}}\right)}+\frac{\Delta y \Delta z}{\left(\frac{\delta x_{e}}{D_{e}}+\frac{\Delta t}{1_{x}}\right)}+\lambda \Delta x \Delta y \Delta z \\
& B_{P}^{C}=\frac{C_{f}^{o} \Delta x \Delta y}{\left(\frac{\delta z_{f}}{D_{f}}+\frac{\Delta t}{1_{z}}\right)}+\frac{C_{e}^{o} \Delta y \Delta z}{\frac{\delta x_{e}}{D_{e}}+\frac{\Delta t}{1_{x}}}+\frac{C_{n}^{o} \Delta x \Delta z}{\frac{\delta y_{n}}{D_{n}}+\frac{\Delta t}{1_{y}}}+\mu S_{P}^{0} \Delta x \Delta y \Delta z
\end{aligned}
$$

b) Solution to the entrapped water concentration

The numerical solution of Equation 4 is obtained by integrating it in volume and time, as follows:

$$
\int_{x} \int_{y} \int_{z} \int_{t} \frac{\partial S}{\partial t} d t d z d y d x=\int_{x} \int_{y} \int_{z} \int_{t}(\lambda C-\mu S) d t d z d y d x
$$

Assuming an explicit formulation, we can write Equation 27 , in the discretized form as follows:

$$
A_{P} S_{P}=A_{P}^{O} S_{P}^{O}+B_{P}^{S}
$$

where,

$$
\begin{gathered}
A_{P}^{o}=\frac{\Delta x \Delta y \Delta z}{\Delta t} \\
A_{P}=\frac{\Delta x \Delta y \Delta z}{\Delta t}+\lambda \Delta x \Delta y \Delta z
\end{gathered}
$$

$$
B_{P}^{S}=\lambda C_{P} \Delta x \Delta y \Delta z
$$

In the discretized form, the local and average moisture contents and the average free water concentration can be written respectively as follows:

$$
M=C+S
$$

$$
\begin{aligned}
& \bar{M}=\frac{1}{V} \sum_{i=2}^{n p x-1} \sum_{j=2}^{n p y-1} \sum_{k=2}^{n p z-1} M_{i, j, k} \Delta V_{i, j, k} \\
& \bar{M}=\frac{1}{V} \sum_{i=2}^{n p x-1} \sum_{j=2}^{n p y-1} \sum_{k=2}^{n p z-1} M_{i, j, k} \Delta V_{i, j, k}
\end{aligned}
$$

From the discretization of the governing equations, a system of algebraic linear equations is generated that must be solved to obtain the values of $\mathrm{C}, \mathrm{S}$ and $\mathrm{M}$ within the material throughout the process. For this, the iterative Gauss-Seidel method was used in a numerical mesh $20 \times 20 \times 20$ control volumes and a time step of 20 seconds, implemented in a computational code in Mathematica ${ }^{\circledR}$ software, after a refinement study.

Table 1. Geometric data used in the simulation

\begin{tabular}{cccccc}
\hline $\mathbf{l x}(\mathbf{m})$ & $\mathbf{l y}(\mathbf{m})$ & $\mathbf{l z}(\mathbf{m})$ & $\mathbf{R x}(\mathbf{m})$ & $\mathbf{R y}(\mathbf{m})$ & $\mathbf{R z}(\mathbf{m})$ \\
\hline 0.126 & 0.0235 & 0.076 & 0.01 & 0.0015 & 0.01 \\
\hline
\end{tabular}

As an application, a specific isothermal case was selected to be studied $\left(\mathrm{T}=25^{\circ} \mathrm{C}\right)$. Table 1 shows the data used in the simulation $\left(\mathrm{D}=7.31787 \times 10^{-12} \mathrm{~m}^{2} / \mathrm{s}, \mu=3.27972 \times 10^{-6} \mathrm{~s}^{-1}\right.$ and $\left.\lambda=2.12852 \times 10^{-6} \mathrm{~s}^{-1}\right)$.

The geometric data used in this application are related to sisal fiber-reinforced polymer composite samples reported by Santos ${ }^{14}$ and the parameters $D, \mu$ and $\lambda$ were estimated using the methodology reported by Joliff et al. ${ }^{13}$ using experimental data of water absorption reported in the literature ${ }^{12}$.

\section{Results and Discussions}

\subsection{Water absorption kinetics}

For this analysis, water absorption curves were plotted as a function of time. Figure 4 shows the kinetics of average moisture content in the composite. The final moisture content value is $0.146893 \mathrm{~kg} / \mathrm{kg}$ achieved after 210,000 seconds ( 58.33 hours). The kinetics shows higher absorption of moisture at initial times of the process and for long timer exists a tendency to reach the equilibrium moisture content (saturation point). These results are consistent with those reported to polymer composites reinforced by other kind of vegetable fibers ${ }^{15-18}$. 
The same characteristic is observed in the kinetics of the average free solute concentration (Figure 5).

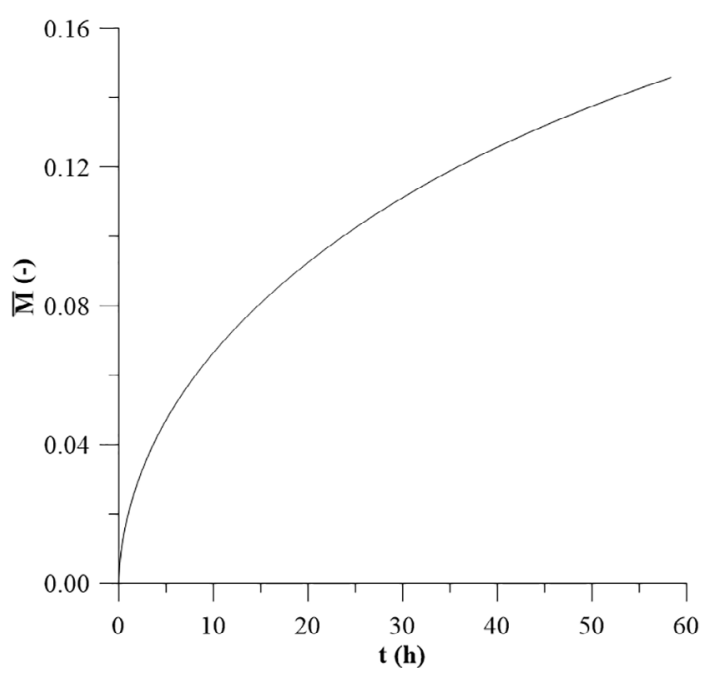

Figure 4. Kinetics of the average moisture content in the composite.

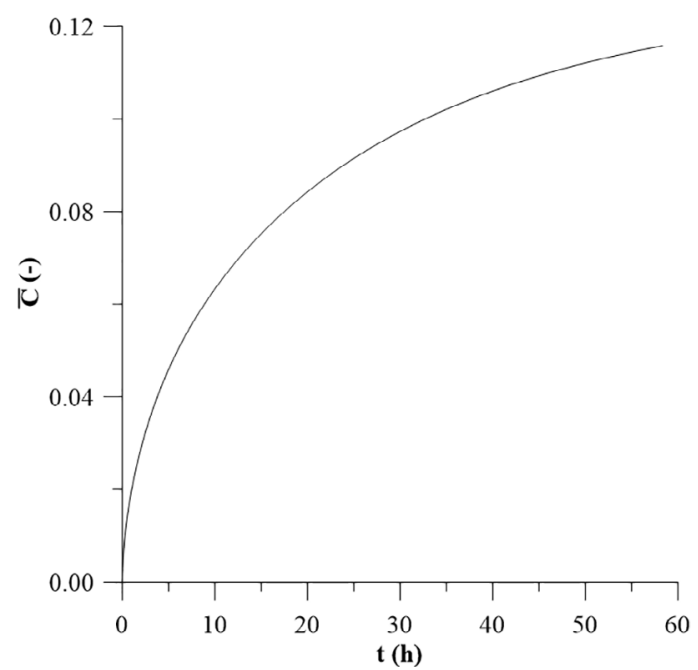

Figure 5. Kinetics of average free water concentration in the composite.

\subsection{Distribution of the free and entrapped water concentrations}

For the analysis of the mass distribution of free water (C) and entrapped water (S) inside the composite, the results of these parameters were plotted in different planes $\left(x=R_{x} / 2\right.$, $\mathrm{z}=\mathrm{R}_{\mathrm{z}} / 2$ e $\left.\mathrm{y}=\mathrm{R}_{\mathrm{y}} / 2\right)$ and times of process $\left(\mathrm{t}_{1}=4500 \mathrm{~s}, \mathrm{t}_{2}=21000 \mathrm{~s}\right.$, $\mathrm{t}_{3}=150000 \mathrm{~s}$ and $\mathrm{t}_{4}=195000 \mathrm{~s}$ ).

Figure 6 illustrates schematically the planes a) $\mathrm{x}=\mathrm{R}_{\mathrm{x}} / 2$, b) $z=R_{z} / 2$ and c) $y=R_{y} / 2$, in the Cartesian plane.

Figure 7 and 8 show the distribution of free solute concentration (C) in the planes $x=R_{x} / 2$ and $z=R_{z} / 2$, respectively. It is observed that the distributions in both planes occur similarly where the points of higher concentrations are at the surface and lower concentrations of free solute occur near the center of the sample (origin of the axis of symmetry).
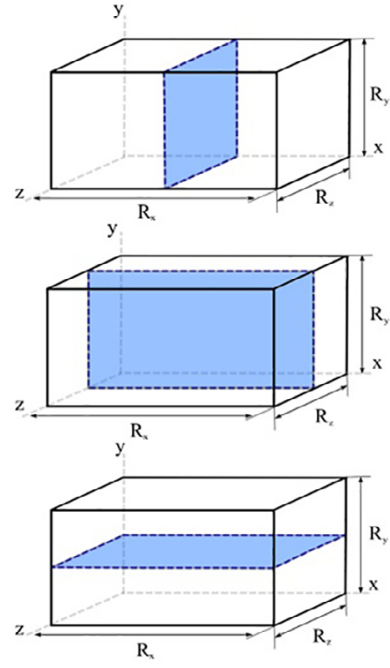

Figure 6. Cartesian planes used to analyze the concentration of free and entrapped solute inside the composite.

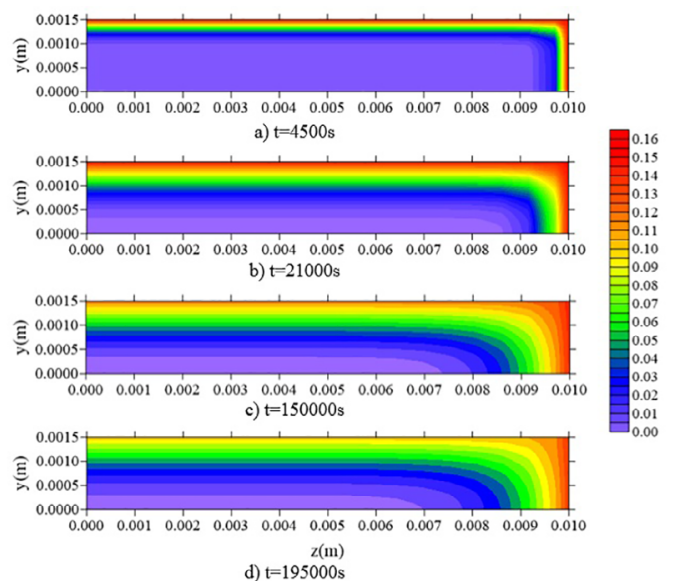

Figure 7. Distribution of the free solute concentration (C) in the $\mathrm{x}=\mathrm{R}_{\mathrm{x}} / 2$ plane for different water absorption times.

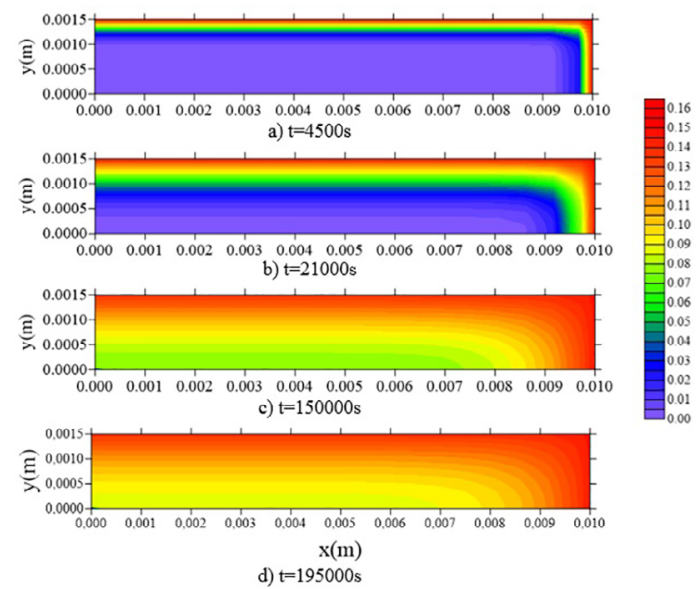

Figure 8. Distribution of the free solute concentration (C) in the $\mathrm{Z}=\mathrm{R}_{\mathrm{z}} / 2$ plane for different water absorption times.

From 150000 s of process, in the plane $\mathrm{z}=\mathrm{R} / 2$, it is verified that the free solute concentration has higher values than in $R_{x} / 2$ plane. 
As the sample recipient has different dimensions then this difference in free solute concentration may be associated with the position of the sample in the recipient considered in the Langmuir's model $\left(1_{x} \neq l_{y} \neq 1_{z}\right)$ and not considered in the Fick's model.

Figure 9 shows the distribution of free solute concentration in the $\mathrm{y}=\mathrm{R}_{\mathrm{y}} / 2$ plane at different water absorption times. It is verified that the free water concentration occurs approximately symmetric in the $\mathrm{x}$ and $\mathrm{z}$ directions, resulting in a higher concentration of free solute at the surface of the sample as expected. Thus, it is verified that the distribution of free solute concentration is in agreement with the mass transport phenomenon described in the literature.

Figures 10 and 11 show the entrapped solute distribution (S) in $\mathrm{x}=\mathrm{R}_{\mathrm{x}} / 2$ e $\mathrm{z}=\mathrm{R}_{\mathrm{z}} / 2$ planes for different times, respectively.
After the analysis of these figures, it is observed that the highest concentration of $\mathrm{S}$ is found on the surface, at $\mathrm{z}=0.01$ $\mathrm{m}$ (Figure 10) and $\mathrm{x}=0.01 \mathrm{~m}$ (Figure 11) and that, at the initial times there is practically no solute concentration entrapped at the surface. By analyzing the $\mathrm{S}$ distributions in relation to $\mathrm{C}$, it can be verified that the free water concentration varies faster than the entrapped water, in the specified planes. So, there is a larger migration of free water inside the sample, which is responsible for the increase of entrapped water inside the composite.

Similarly to what occurs at $\mathrm{C}$ parameter, Figure 12 , that shows the distribution of $\mathrm{S}$ in $\mathrm{y}=\mathrm{R}_{\mathrm{y}} / 2$ plane for different times, evidences that the behavior of the entrapment of the solute occurs almost symmetrically in the $\mathrm{x}$ and $\mathrm{z}$ directions.

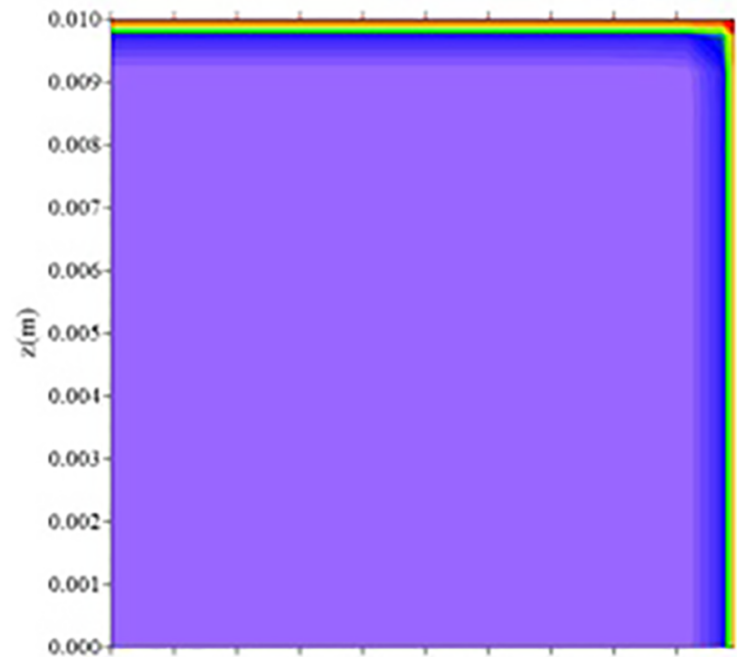

a) $t=4500 \mathrm{~s}$

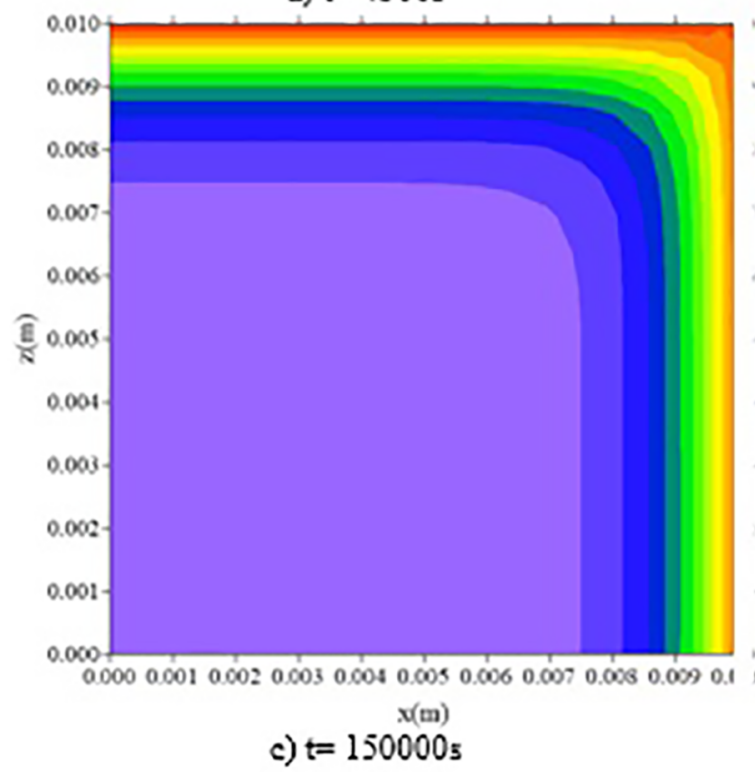

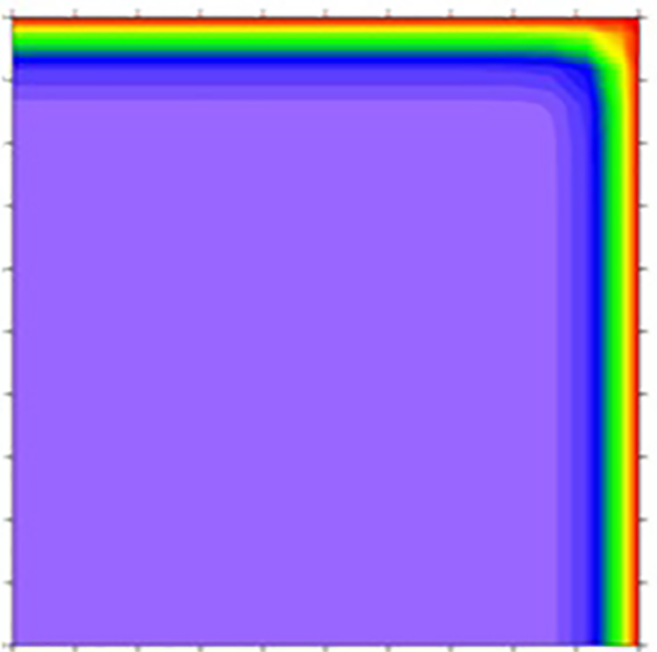

b) $t=21000 \mathrm{~s}$

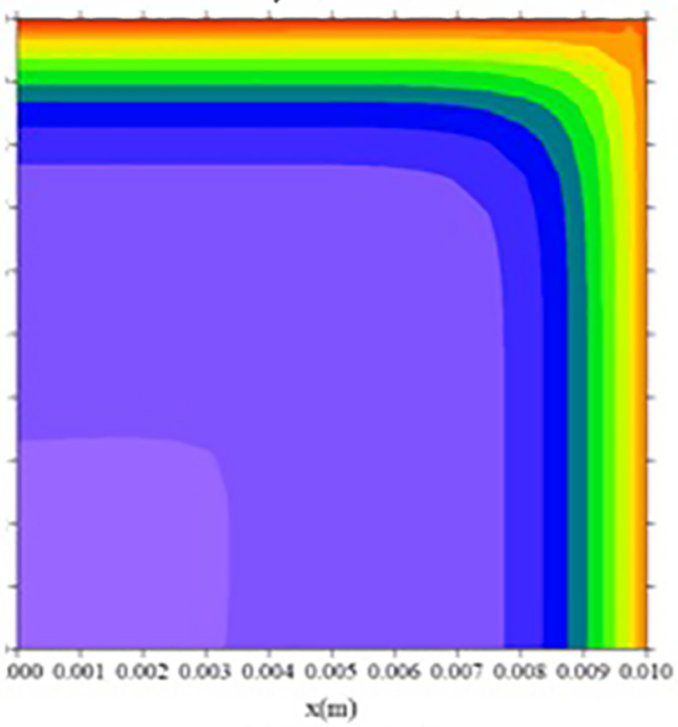

d) $\mathrm{t}=195000 \mathrm{~s}$

Figure 9. Distribution of the free solute concentration $(C)$ in $y=R_{y} / 2$ plane for different water absorption times. 

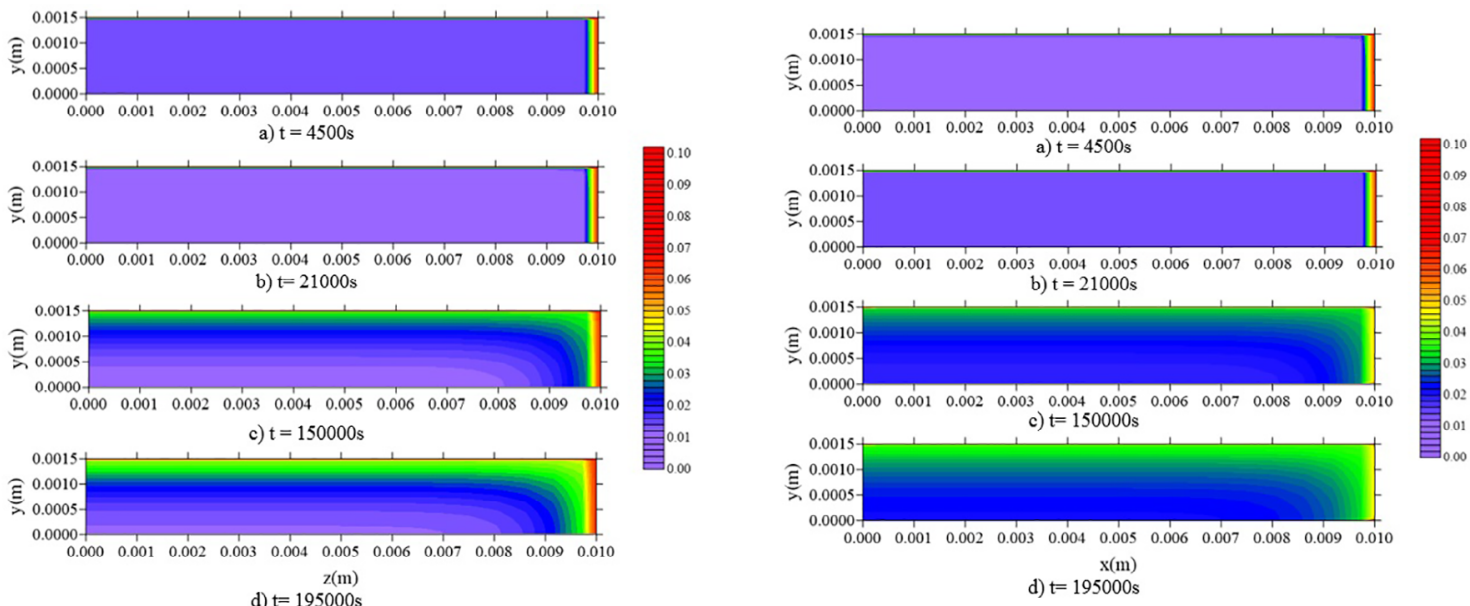

$$
\text { d) } \mathrm{t}=195000 \mathrm{~s}
$$

Figure 10. Distribution of the entrapped solute concentration (S) in $\mathrm{x}=\mathrm{R}_{\mathrm{x}} / 2$ plane for different water absorption times

Figure 11. Distribution of the entrapped solute concentration (S) in $\mathrm{z}=\mathrm{R}_{\mathrm{z}} / 2$ plane for different water absorption times.

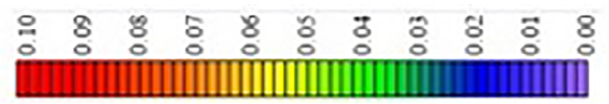

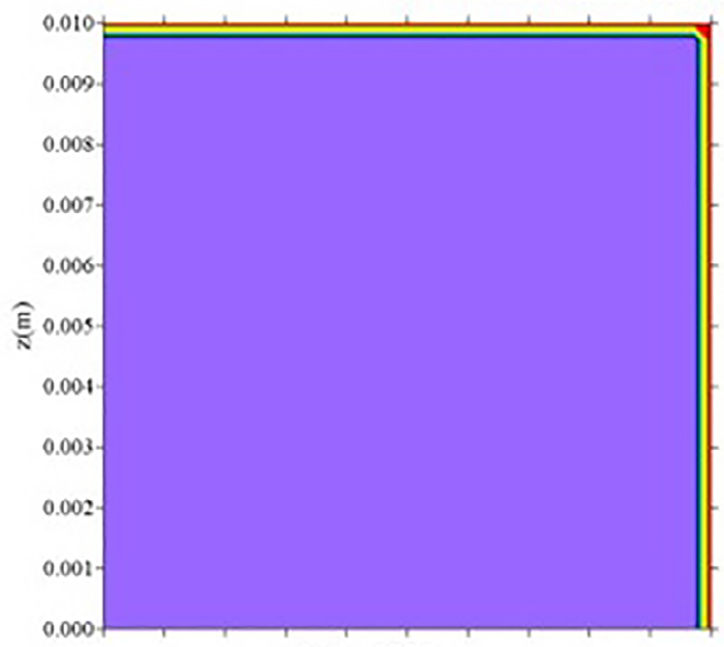

a) $t=4500 \mathrm{~s}$

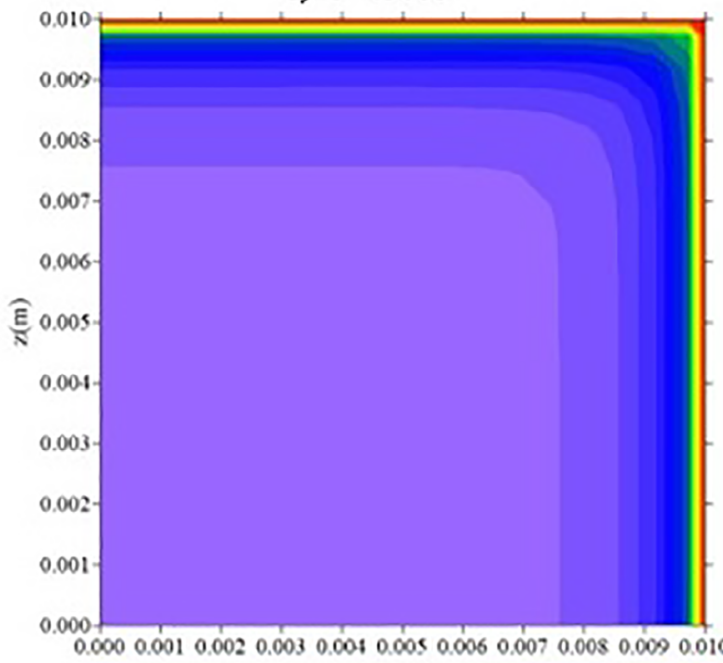

$x(m)$

c) $t=150000 \mathrm{~s}$

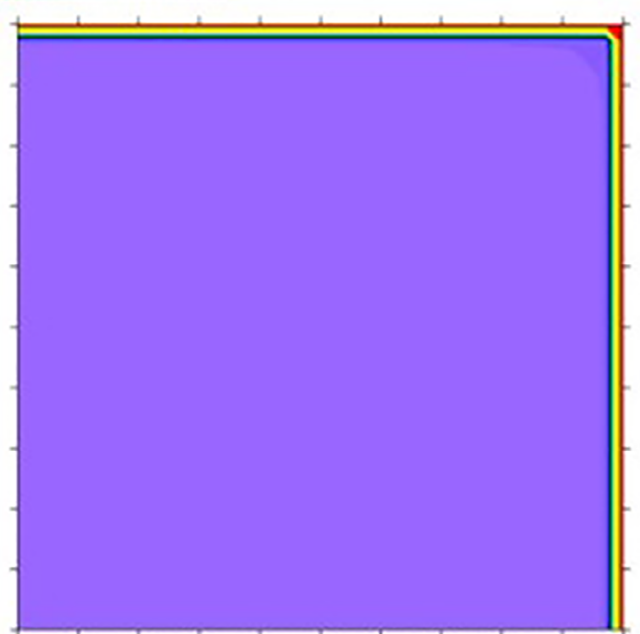

b) $t=21000 \mathrm{~s}$

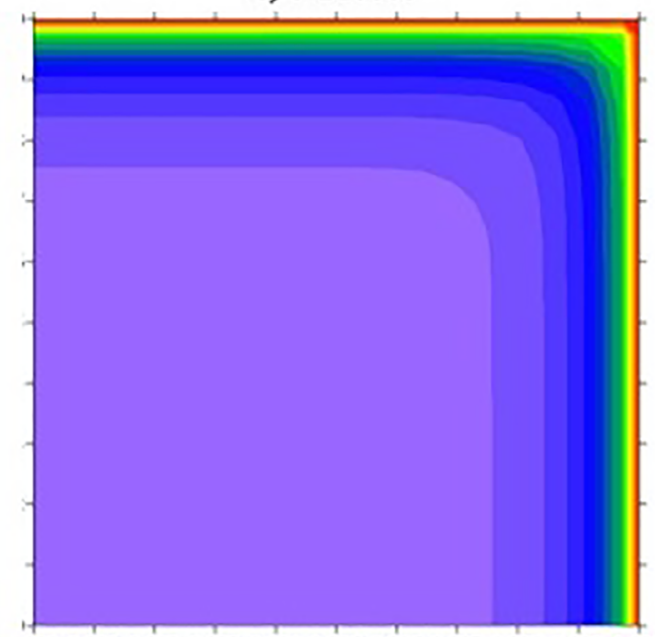

0000.0010 .0020 .0030 .0040 .0050 .0060 .0070 .0080 .0090 .016 $\mathrm{x}(\mathrm{m})$

d) $\mathrm{t}=195000 \mathrm{~s}$

Figure 12. Distribution of the entrapped solute concentration $(S)$ in $y=R_{y} / 2$ plane for different water absorption times. 
It can be verified, in general, that the entrapped solute concentration (S) is lower than the free solute concentration (C) at any point inside the composite and at any time of process. In addition, as the concentration of free water increases, there is also an increase in entrapped water concentration within the material, showing a strong correlation between these two parameters.

\section{Conclusions}

In this research a three-dimensional and transient mathematical modelling and its numerical solution, to describe the water absorption in polymer composites reinforced by fiber were presented. From the obtained results, it can be concluded that:

a) The numerical solution of the Langmuir model was appropriate and the obtained results were consistent with the mass transport phenomenon inside the material;

b) The highest moisture absorption occurs at the initial times of the process tending to equilibrium for long times;

c) The free solute concentration increases faster that the entrapped solute concentration at any time of the process and at any point inside the composite;

d) The molecules concentration gradients (free and entrapped) are higher close to the surface of the material;

e) There is a strong correlation between the free and entrapped solute concentration, verified by their simultaneous increase.

\section{Acknowledgements}

The authors thank CNPq, CAPES and FINEP (Brazilian Research Agencies) for the financial support and the authors cited in the text.

\section{References}

1. American Society for Testing Materials (ASTM). D387801 - Standard Terminology for Composite Materials. West Conshohocken, PA: ASTM International; 2007.

2. Espert A, Vilaplana F, Karlsson S. Comparison of water absorption in natural cellulosic fibers from wood and one-year crops in polypropylene composites and its influence on their mechanical properties. Composites Part A: Applied Science and Manufacturing. 2004;35(11):1267-1276.

3. Melo RQC, Santos WRG, Lima AGB. Applying the LangmuirType mass transport model on the water absorption in vegetable fiber reinforced polymer composites: a finite-volume approach. Proceedings of the XXXVIII Ibero-Latin American Congress on Computational Methods in Engineering - CILAMCE; 2017 nov. 5-8; Florianópolis (SC), Brazil. Florianópolis (SC): CILAMCE; 2017. p. 1-14.
4. LaPlante G, Ouriadov AV, Lee-Sullivan P, Balcom BJ. Anomalous moisture diffusion in an epoxy adhesive detected by magnetic resonance imaging. Journal of Applied Polymer Science. 2008;109(2):1350-1359.

5. Alomayri T, Assaedi H, Shaikh FUA, Low IM. Effect of water absorption on the mechanical properties of cotton fabricreinforced geopolymer composites. Journal of Asian Ceramic Societies. 2014;2(3):223-230.

6. Yu B, Yang J. Hygrothermal effects in composites. In: Hashmi S, editor. Reference Module in Materials Science and Materials Engineering. Amsterdam: Elsevier; 2017. p. 502-519.

7. Bond DA, Smith PA. Modeling the transport of low-molecularweight penetrants within polymer matrix composites. Applied Mechanics Reviews. 2006;59(5):249-268.

8. Peret T, Clement A, Freour S, Jacquemin F. Effect of mechanical states on water diffusion based on the free volume theory: Numerical study of polymers and laminates used in marine application. Composites Part B: Engineering. 2017;118:54-66.

9. Maggana P, Pissis P. Water sorption and diffusion studies in an epoxy resin system. Journal of Polymer Science Part B: Polymer Physics. 1998;37(11):1165-1182.

10. Glaskova TI, Guedes RM, Morais JJ, Aniskevich AN. A comparative analysis of moisture transport models as applied to an epoxy binder. Mechanics of Composite Materials. 2007;43(4):377-88.

11. Carter HG, Kibler KG. Langmuir-Type model for anomalous moisture diffusion in composite resins. Journal of Composite Materials. 1978;12(2):118-131.

12. Peret $\mathrm{T}$, Clément $\mathrm{A}$, Freour $\mathrm{S}$, Jacquemin F. Numerical transient hygro-elastic analyses of reinforced Fickian and non-Fickian polymers. Composite Structures. 2014;116:395-403.

13. Joliff Y, Belec L, Chailan JF. Modified water diffusion kinetics in an unidirectional glass/fiber composite due to the interphase area: Experimental, analytical and numerical approach. Composite Structures. 2013;97:296-303.

14. Santos DG. Hygrothermal study and mechanical chacterization of polymer matrix composite reinforced with vegetable fiber: 3 Dimulation and experimentation [thesis]. Campina Grande, Brazil: Federal University of Campina Grande; 2017.

15. Silva CJ, Lima AGB, Silva EG, Andrade THF, Melo RQC. Water Absorption in Caroá-Fiber Reinforced Polymer Composite at Different Temperatures: A Theoretical Investigation. Diffusion Foundations. 2017;10:16-27.

16. Santos DG, Lima AGB, Pinto MVS. Mechanical Characterization and Water Sorption in Polyester Matrix Composites Reinforced with Sisal Fiber: An Experimental Investigation. Defect and Diffusion Forum. 2016;369:131-134.

17. Santos DG, Lima AGB, Costa PS. The Effect of the Drying Temperature on the Moisture Removal and Mechanical Properties of Sisal Fibers. Defect and Diffusion Forum. 2017;380:66-71.

18. Bezerra AFC, Cavalcanti WS, Lima AGB, Souza MJ, Porto TRN. Unsaturated polyester composite reinforced with Caroá fiber (Neoglaziovia Variegate): water sorption and mechanical properties. Revista Materia. 2017;22(2):e11842. 